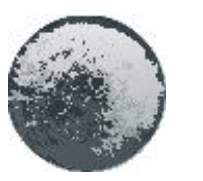

\title{
ЭКОЛОГИЧЕСКОЕ ОБРАЗОВАНИЕ: ПЕРСПЕКТИВЫ РАЗВИТИЯ
}

\author{
Элеонора Л. Мельник \\ Карельский институт туризма Филиал НОУ ВПО \\ Российская академия туризма, Петрозаводск, Россия
}

\begin{abstract}
Аннотация
Признавая существующие проблемы окружающей среды, современное человечество пытается найти с ней новые способы взаимодействия. С одной стороны это - развитие инновационных технологий организащии производств, сберегающих природные ресурсы и направленных на оздоровление среды обитания. С другой интродуцировать знания об окружающей среде во все сферы человеческого образования. Психологическая наука утверждает, что человек постиндустриального общества духовно отдален от природы, а усиливающаяся его формальная религиозность не мешает становлению прагматичных взглядов на свое бытие. Стремление получить от жизни «все» «здесь и сейчас» оказало свое влияние на формирование иенностей. Они изменились не в лучиую сторону. Вернуть былье утратьл в отношениях к природе, людям, к предметам культуры, т.е. изменить ментальность человека в отношениях с внешней средой, с самим собой, значит сменить стиль мышления с отрицания среды на принятие и понимание ее законов. Процесс перестройки мышления человека длительный. Он требует организации специильных институтов, которые бы могли заниматься этими вопросами с раннего детства, так чтобы ребенок понимал роль среды как главную ценность в жизни для сохранения всего живого на земле. Поэтому необходимо, чтобы учащиеся хотели, а педагоги могли совместно осуществлять этот процесс. Статья основывается на анализе педагогической, психологической, философской, методической литературы, собственных наблюдениях, опыте работы в области знаний об окружающей среде с учашимися младшего школьного возраста, их родителями и учителями.
\end{abstract}

Ключевые слова: мышление человека, окружающая среда, экологическое образование.

\section{Введение}

Принятие в конце 20 века большинством стран мирового сообщества концепции «Устойчивого развития» свидетельствует о том, что человечество было вынуждено изменить сложившееся отношение к среде обитания и направить усилия на ликвидацию отрицательных последствий своей деятельности. Отношения человека со средой обитания - это мировоззренческая проблема, а смена сознания отдельного человека и общественных групп - процесс сложный и длительный. Поэтому необходимы усилия многих современных специалистов в области окружающей среды для того, чтобы мотивировать молодежь на изучение закономерностей развития среды обитания, сохранения и ее модернизации. В этом контексте, идеи о единстве «Человека и Мира», «Человека и Природы», высказанные великими учеными - Le Roy E (1927), Тейяр де Шарденом (1987), Вернадским (1988), Чижевским (1976), Рубинштейном(1957), Моисеевым (190), остаются актуальными и в наше время. Отражение этих мыслей получило развитие 
в теории психологии человека - субъекта. Однако не каждый индивид является субъектом своей деятельности и общения. Человек становится субъектом, когда он понимает собственное бытие так, что, осознавая объективность и сложность своих проблем, он одновременно обладает ответственностью и силой для решения возникших сложностей (Брушлинский, 2003).

Целостность человека - субъекта является тем основанием, которое позволяет говорить о системности всех его психических качеств- достаточно противоречивых и не всегда гармоничных [Брушлинский, 1996]. Но в обыденной жизни человек не всегда осознает свое личное существование, как целостность субъекта и объекта, т.е. себя в единстве с внешним миром. Эта целостность обретается им, в критических ситуациях, после которых, человек уже приобретает способность «выбирать себя» и формировать себя каждым поступком и действием, неся ответственность за все сделанное им самим в окружающем его пространстве. В философии экзистенциального эта категория отношений человека с собой и с внешней средой, определяется как «свобода». А свободный человек сам несет ответственность за свои деяния, не ссылаясь на внешние «обстоятельства» и не оправдывая свои поступки только ситуацией из вне (Хайдеггер, 1997). Бердяев (1993) также утверждал, что чувство вины за все совершающееся вокруг человека это чувство свободного человека. К сожалению, чувство вины за негативные результаты своего влияния на среду и для отдельного человека, и для различных групп людей, свойственно не всем. Однако развитие этого чувства у человека позволило бы ему дистанцироваться от конформизма и приспособленчества в современном мире и приблизило бы его к тому идеальному психическому состоянию человека, которое называется субъектным. Субъект - это всеохватывающее, наиболее широкое понятие человека, обобщенно раскрывающее неразрывно развивающееся единство, целостность, системность всех его качеств: природных, общественных, индивидуальных (Брушлинский, 2003; АбульхановаСлавская, 1977). Субъектом человек не рождается, а становиться. Оптимальное время для развития субъектных свойств человека приходится на младший школьный возраст. Начало же становления человека - субъекта - 7-9 лет, но наращивание субъектного потенциала продолжается всю жизнь.

Эту научную истину следует донести до широкого круга специалистов, работающих с детьми. Особенно до сознания тех, кто занимается экологическим образованием с детьми. Необходимо помнить, что экологические проблемы среды, их плюсы и минусы, которые складываются на уровне стран, регионов, областей и отношения, которые инициируются человеком в этих условиях в процессе взаимодействия его со средой, конструируют стиль поведения людей. Сформированная модель поведения копируется и воспроизводится в жизни и деятельности последующих поколений детей и молодежи.

Произошедшая смена ценностных ориентиров изменила взгляды людей на окружающую среду. Появление новых технологий в промышленности, в образовании с современным информационным пространством, с одной стороны стало способствовать усилению коммуникабельности человека, его независимости от внешней среды. С другой - превращается в составную часть развития процесса реального одиночества человека в современном мире, ухода его от чувственноконтактной формы между людьми, компонентами естественной природной среды, формализуя и отчуждая всех их от своих носителей. Отношения же человека с новой средой, приобретают преимущественно, прагматическую форму: прежде всего, удовлетворение плоти - секс, пища, деньги. Реализация потребностей 
диктуется необходимостью получения всего «здесь и сейчас» по принципу: «полезно -неполезно», «значимо-незначимо», «интересно -неинтересно». Духовная жизнь не является необходимым условием успешности в карьерном росте для большинства индивидуумов из числа современной молодежи.

Поэтому с позиций образования, при сложившихся реалиях, необходимо культивирование нового стиля отношений человека с природой, с обществом, людей друг с другом для сохранения ресурсов окружающей среды, в том числе и человека. Однако следует иметь в виду, что сознание, как форма бытия человека обладает свойством «запаздывания» в оценке ситуаций. Этот процесс, выражается в том, что проблема человека и среды уже существует и развивается, а психологически общество еще не готово к конструктивным переменам в своей деятельности. В этой ситуации, естественнонаучное образование детей и молодежи могло бы ускорить формирование новых, не прагматических взглядов человека на мир, что, несомненно, способствовало бы выстраиванию позитивных отношений со средой жизни. Однако, ряд дисциплин, таких как, биология, химия, и физика не включаются в список приоритетных знаний выпускников школ в России. На этом фоне, организаторами от образования, предлагается уделить значительное внимание воспитательному процессу, в том числе и экологическому. Но, процесс воспитания и обучения детей не должен рассматриваться изолировано друг от друга, они составляют целостную систему, которая предполагает их единство и одновременность усилий педагогов по реализации: знаний о природе и явлениях, умений, навыков, конструирования отношений мотивированных желаниями и поступками - хочу, могу, делаю, буду делать, научу других. В целом, в структуре знания о среде, как системе, естественнонаучное и гуманитарное, взаимосвязаны. В российской педагогической науке, проблема взаимодействия человека с окружающей средой всегда рассматривалась в рамках теории и практики экологического обучения и воспитания. Основоположниками данного направления были - Захлебный (1981), Зверев (1992). Мамедов (1995), Пономарев (1975), Розанов (1984), Рыжов (2001), Суровегина (1986) и ряд других, которые разработали концепцию непрерывного экологического образования в России. Необходимость непрерывного экологического обучения и воспитания мотивировалась следующими положениями:

1) потребностью изменения целей во взаимодействиях с природой, основанных на ее покорении и доминирующих в структурах сознания современного человека;

2) необходимостью поиска новых конструктивных отношений со средой в условиях сохранения и функционирования техногенного общества заменой непродуктивных отношений человека со средой на наиболее адекватные отношения - сотрудничества и равноправия;

3) формированием нового мышления людей о природе.

В то же время, надо отметить, что экологическое сознание человека не может быть сформировано в отрыве от его обыденного бытия, поскольку оно является частью целостного мировоззрения человека, которое выявляется при взаимодействии с природой и в другой повседневной практике человека (в жизни семьи, общества в целом, в отношении к самому себе).

К сожалению, при реализации поставленных целей, в процессе обучения и воспитания акцент был сделан на экологизацию школьных (вузовских) предметов, создание специализированных учебных заведений, но не на межпредметную или междисциплинарную составляющую образования. Поэтому, произошла подмена 
интегрированного, по своей природе экологического образования, биологическим как основным и единственным, в общей системе ценностей, которые формируют отношения человека со средой и его экологическую составляющую. То есть, многообразие природных и социальных явлений окружающего мира оставались не изученными, поскольку не служили предметом исследования биологии.

Подтверждением этой точки зрения явились результаты исследования, которые показали низкую заинтересованность населения проблемами окружающей среды, отсутствием базовых теоретических знаний о природе у молодежи и школьников, осознанных отношений, умений устанавливать взаимосвязи между социальными, экономическими и экологическими проблемами, а также слабую инициацию использования теоретических знаний на практике. Очевидно в связи с этим фактом, в ответах учащихся на первом месте находятся антропоцентрические потребительские ценностные аспекты (Мельник, 2005; 2006). В то же время, психологи отмечают, что вовлечение ребенка в процесс познания окружающей среды на уровне чувств, эмоций, знаний, убеждений, психологических навыков приводит к формированию новой этики и эстетики отношений в современной цивилизации человека, задает позитивный характер развития отношений со средой. Надо отметить, что чувственный опыт, полученный в раннем детстве, является самым значимым личным аргументом в отношениях со средой. В процессе становления ответственности за окружающую среду этот опыт продолжает влиять и на взрослую жизнь человека. Теория и практика экологического образования также показала, что крайне важно в педагогической деятельности развивать у субъекта «инстинкт местности», складывающийся из знаний о своем крае и умений, которые в практической жизни позволяют ребенку сопоставлять их с реальной ситуацией, выстраивая тип отношений в будущем.

\section{Мировоззренческая составляющая экологического образования}

Данный аспект в педагогической практике недостаточно полно представлен в системе дополнительного, школьного и вузовского образования. Отметим некоторые проблемные моменты, которые следует решать в процессе формирований новых отношений человека со средой.

А. Необходимость осознания человеком и обществом факта антропогенного влияния на окружающую среду

Осознание человеком негативного антропогенного воздействия на окружающую его среду достигается постепенно, в результате обучения и воспитания в семье, дошкольных, школьных, средних и высших учебных учреждениях. Педагогическая задача состоит в том, чтобы направить усилия самого человека на осознание его роли в мире. Определить его перспективное видение среды. Выяснить его причастность к миру - он «внутри» мира, «вне» его или «над ним» и выстроить соответствующие этому пониманию систему знаний, в которой среда выступала бы, как главная ценность в жизни и деятельности.

Б. Осущчествить интервенцุию системного подхода в понимании эволющчи мира и эволюции отношений человека с ним. 
Из истории стилей отношений установлено, что человек - первобытный был ближе к природе, нежели наш современник. Исследования выявили существенные нарушения в его отношениях к природе, их несбалансированность, прагматизм. Вполне обоснованной является критика расточительных и потребительских отношений человека с природой. В качестве альтернативных отношений предлагается развивать паритетные и конструктивные отношения между человеком и средой его жизни, по принципу «и камень имеет право». При дифференцированном подходе к проблеме отношений человека и среды всегда существует опасность в том, что сам человек как личность, общество в целом, его культура, мораль и нравственность отойдут на второй план. В этом контексте характер современных отношений общества со средой должен выстраиваться на основе таких принципов, как субординация, координация, корреляция. Необходимо исследовать порядок взаимосвязей, характер взаимосвязей частей и трансформацию самих частей в окружающем пространстве, среди которых принцип оптимального соответствия общества и природной среды является главным.

В. Отсутствие современной интегральной оценки (диагностики) характера отношений человека со средой обитания в историческом аспекте

Природа для современного человека представлена двумя уровнями: либо природными ресурсами, либо охраняемыми территориями. Живое, трепетное общение с природой замещается на ее суррогат - измененную природную среду. Усиливается тенденция виртуального контакта с элементами природы.

Духовный аспект природы в жизни человека занимает второй план.

Г.Игнорирование принцฺипа полифункциональности отношений человека $к$ пониманию роли окружающей средь

На сегодняшний день признается отсутствие в теории и практике соответствующих времени педагогических технологий, обеспечивающих ориентацию детей в процессе общения с природой на ценности, которые не связаны с прагматизмом. Поэтому необходима концентрация усилий различных наук, направленных на изучение не только отношений «Человек- Природа», но и значительно шире «Человек - Окружающая среда».

Экологическая психология предлагает рассматривать отношения человека и среды как проблему самого человека, его целостного сознания. Характер этих отношений можно рассматривать в трех уровнях:

1) отношения отдельного субъекта с естественной природной средой

2) отношения с другими людьми - между человеком и обществом, представленные как отношения человека и техносферы (вся совокупность используемых человеком технических средств);

3) отношения человека с самим собой, т. е. с перманентной, внутренней противоречивостью его самого.

Все три уровня отношений человека со средой имеют различный характер проявлений их во внешней среде в различных общественных группах, которые неоднородны:

а) по территориальному признаку;

б) по межнациональному и межэтническому признаку;

в) по профессиональным обязанностям (корпоративности); 
г) по социальной принадлежности (семья, организация, партия).

Сформированные те или иные отношения между членами общества (ставшие приемлемыми и принятыми большинством) транслируются и распространяются на объекты природы (естественные), на новый предметный мир, на «вторую природу», становясь основополагающими мотивами к поведению и деятельности людей молодого возраста, тех, кто вступает трудовую жизнь. То есть общество в целом воспроизводит тот тип отношений к окружающей среде и в окружающей среде, который отвечает современным взглядам человека той или иной общности на свое бытие.

На этом фоне, варианты решения современных проблем экологического образования, которые бы характеризовали и развивали отношениями человека со средой в будущем, могут выглядеть следующим образом:

1) исследование непосредственного близкого окружения человека, включающего различный состав предметов и людей в пространстве (изба, усадьба, семья)

2) изучение взаимосвязей между переменными среды и различными характеристиками психики человека (иллюстрация контрастных способов организации окружающей среды;

3) изучение связей между поведением человека и материальной средой его окружения.

В этой связи результаты работы педагога по экологическому образованию, не должны оцениваться как «быстрые», поскольку смена ценностных ориентиров человека происходит постепенно. Более того, в процессе обучения и воспитания, мотивационные, поведенческие установки, навыки и умения складываются благодаря только системному и характеру в педагогической деятельности.

Применительно к системе экологического образования детей и молодежи целесообразно также рассмотреть и такие параметры, как: непосредственные результаты образовательной деятельности - знания, умения, навыки и виды деятельности, достижения и опосредованные - изменения в общественной жизни человека, его поведении, отношениях с природой и людьми.

Теория и практика образования в области окружающей среды в контексте проблем экологического обучения и воспитания на современном этапе

1. Автор является сторонником положения о том, что знания представляют основу любого образования. Содержание экологического образования, как части общего образования, его комплексный и интегрированный характер может обеспечить учащимся всестороннее изучение окружающей среды. Природа, человек и общество - биологическое и социальное - генетическое единство бытия должно найти свое отражение в стандартах образования программах, учебниках, учебно-методической литературе и др.

2. Содержание образования определяет форму обучения. Традиционные уроки, занятия на природе, экскурсии, учебно-исследовательская и проектная деятельность учащихся.

3. Осуществление непрерывного образования в области окружающей среды: с детства до преклонных лет.

4. Преемственность образования - от прошлого в настоящее и будущее, как знаний, так и традиций в отношениях с природой и людьми. 


\section{Заключение}

Анализ проблемы экологического образования в России говорит о том, что интерес молодежи к естественным наукам находится на уровне других европейских стран и он не высок. Однако, в результате реформ школьного и вузовского образования предметы естественнонаучного цикла получили статус «предметов по выбору». Можно ожидать, что при низкой заинтересованности такими предметами как физика, химия и биология, количество желающих получить знания будет снижаться. Учитывая демографическую ситуацию в стране, соответственно, можно прогнозировать и потерю учебной нагрузки педагогами, их не востребованностью и, в конечном счете, к потере педкадров для школы и вуза. Поэтому, перечисленные выше проекты по реанимированию экологического образования с целью улучшения экологической обстановки в стране и сохранения природы остается в качестве научных проектов. То есть, понимание необходимости улучшения образования в стране существует, но оно находится в стадии формального декларирования.

\section{Литература}

Le Roy E. (1927). L'exigence idealiste et le fait de l'evolution. Paris.

Тейяр де Шарден П. (1987). Феномен человека. Москва.

Вернадский В. И. (1988). Философские мысли натуралиста. Москва.

Чижевский А. Л. (1976). Земное эхо солнечных бурь. Москва: Мысль, 246 с.

Рубинштейн С. Л. (1957). Бытие и сознание. Москва: Изд-во АН СССР, 328 с.

Моисеев Н. Н. (1990). Человек и ноосфера. Москва: Молодая гвардия, 351 с.

Хайдеггер М. (1997). Бытие и время. Москва, 437 с.

Бердяев Н. А. (1993). Человек. Микрокосм и макрокосм. Феномен человека. Москва.

Брушлинский А. В. (2003). Психология субъекта. Москва: Ин-т психологии РАН; СПб.: Изд-во «Алетейя».

Абульханова-Славская К. А. (1977). Диалектика человеческой жизни. Москва: Мысль, $224 \mathrm{c}$.

Захлебный А. Н. (1981). Школа и проблемы охраны природы: (Содержание природоохранного образования). Москва: Педагогика, 184 с.

Зверев И. Д. (1992). Методология проблемы отношения личности к природе. В кн.: И. Д. Зверев, И. Т. Суровегина, Современные подходы $\kappa$ содержанию $u$ организачии непрерывного экологического образования. Санкт-Петербург.

Мамедов Н. М. (1995). Концепция устойчивого развития и экологической образование. В кн.: Н. М. Мамедов, Экология и география: проблемы подготовки учителя: тез. докл. Москва.

Пономарев Я. А. (1975). О так называемой биосоциальной проблеме. В кн.: Я. А. Пономарев, Соотношение биологического и социального в человеке. Москва: ВНО НиП.

Розанов Б. Г. (1984). Основы учения об окружающей среде: учеб. Пособие. Москва: Изд-во Моск. ун-та, 376 с.

Рыжов И. Н. (2001). Восприятие окружающей среды городскими школьниками. География в школе, 3, 63-66.

Суровегина И. Т. (1986). Теория и практика формирования ответственного отношения школьников к природе в проиессе обучения биологии: автореф. дис. ... докт. пед. Наук. Москва, 36 с.

Мельник Э. Л. (2005). Ориентация младших школьников в окружающей среде. В кн.: Natural Science Education at a General School (Proceedings of the Eleventh National Scientific Conference, XI). Siauliai, 136. 
Мельник Э. Л. (2006). Ориентация детей и взрослых в окружающей среде. В кн.: Ребенок в современном обществе: психолого-педагогические аспекты развития, воспитания и обучения: материаль межвузовской научно-практической конференции 19-20 октября 2006 года, Петрозаводск/отв. за вып. И.Л. Гольдфельд [и др]. Федеральное агенство по образованию, ГОУВПО «КГПУ». Петрозаводск, 388 с.

\title{
Summary
}

\section{ENVIRONMENTAL EDUCATION: PERSPECTIVES OF DEVELOPMENT}

\author{
Eleonora L. Melnik \\ Karelian Institute of Tourism, Branch of Russian International Academy of Tourism, Pet- \\ rozavodsk, Russia
}

Realizing existing environmental problems the contemporary humanity is seeking new ways of interaction with environment. On the one hand it lies in development of innovative technologies in manufacturing process which reserve natural resources and focus on enhancement of environment. On the other hand it implies introduction of environmental knowledge into all spheres of education. Psychological science claims that a person of postindustrial society is spiritually distanced from nature and the increasing formal religiosity doesn't prevent them from developing a pragmatic view on their being. Striving to take everything from life "right now and right here" has made an impact on development of values. They have changed for the worse. The process of human mentality change is long-term. It requires organization of special institutions which would study these issues from the early childhood to make a child understand the role of environment as the most important value needed for preserving the life on the Earth. That is why it is very important for children to want and for teachers to able to carry out this process jointly. World viewing component of environmental education is intended to find out human's belonging to the world - whether a person is "in" the world, "out" of world or "above" the world - and to organize the system of knowledge which would correspond to this understanding of human's place in the world where environment would act as the main value of life and work. It is significant to change the character of relationships between the contemporary society and the environment; it should be developed on the basis of such principles as subordination, coordination and correlation. It is necessary to research the order of interrelations, the character of interrelation of elements and transformation of elements in the environment. Supporting the statement that knowledge is the basis of any education we claim that the content of environmental education being a part of general education with its complex and integrated character can provide comprehensive study of the environment to students. Nature, human being and society - biological and social - genetic unity of existence should be reflected in education standards: programmes, study-books, methodological literature, etc. The content of education determines the form of training: traditional lessons, outdoor training, excursions, research and project activity of students. Environmental education should have lifelong character: from childhood till elderly. Continuity of education - from the past to the present and future- should be implemented in the sphere of knowledge as well as in the sphere of traditional relationships with nature and people. It is also reasonable to consider such characteristics as direct results of educational activity - knowledge, skills, experience, kinds of activity and achievements; and indirect results - changes in social life of humans, their behavior and relationships with nature and people.

On the whole the analysis of the problem of environmental education in Russia shows that the interest of young people to natural science is on the same level of that in other European countries and it is not high. However as a result of reforms of secondary and higher edu- 
cation the natural science subjects have become electives. It can be expected that low level of interest to such subjects as physics, chemistry and biology will turn into decrease of number of those who would like to get knowledge of these subjects. Considering the demographic situation in the country we can predict decline of teaching load, absence of demand for such teachers and, at the end, loss of pedagogical staff in schools and universities. That is why mentioned above projects on upgrading environmental education with the goal to improve the environmental situation in the country and nature preservation remain in the status of scientific projects. That is to say that there is an understanding of the necessity to improve education for better life in the country but now it is still on the stage of formal declaration.

Key words: environmental education, environmental knowledge, values of life.

Received 28 October 2012; accepted 30 November 2012

\section{DEenora L. Melnik
Eleon}

PhD., Associate Professor, Karelian Institute of Tourism, Branch of Russian International Academy of Tourism, Petrozavodsk, Russia

E-mail: mel.nor@mail.ru

Website: http://www.karit.ru/ 